\title{
La publicidad del vestido ${ }^{1}$
}

\author{
Vanni CODELUPPI \\ Università di Modena e Reggio Emilia ${ }^{2}$
}

\begin{abstract}
RESUMEN:
La publicidad del vestido es uno de los ámbitos publicitarios de mayor importancia porque las empresas de este sector invierten muchos recursos económicos en todas sus actividades de comunicación. Sin embargo, el lenguaje que utilizan estas acciones es por lo general muy elemental, sobre todo en lo que se refiere al medio que emplean con más asiduidad: las revistas. A pesar de ello, es posible analizar las modalidades de comunicación de los mensajes publicitarios del vestido. Este artículo, basado en el análisis de un amplio corpus de anuncios gráficos, muestra que en la publicidad del vestido se ponen en marcha principalmente seis estrategias comunicativas.
\end{abstract}

PALABRAS CLAVE: Publicidad; vestido; fotografía; imagen; estrategia comunicativa.

TITLE: Clothes advertising

ABSTRACT: Clothes advertising is one of the most important because brands invest a lot of money in it. Nevertheless, the language used in the advertisements is very basic, even more in magazines. This paper shows that clothes advertising uses six main communication strategies

KEY WORDS: Advertising, clothes; photography; image; communicative strategy.

\section{Introducción}

La publicidad del vestido ha utilizado siempre como principal instrumento la imagen fotográfica. De hecho, gracias a ella cobra vida el cuerpo imaginario sobre el que se rige el sistema de la moda, ese cuerpo deseable hasta el punto de producir un fuerte efecto de identificación e imitación. Pero en la actualidad la publicidad destinada al vestido pocas veces es capaz de crear imágenes que permanezcan realmente impresas en la mente de las personas. En la mayoría de las ocasiones se limita a un «parloteo» insistente que se desliza dejando poquísimas huellas tras de sí. Por lo general, se sigue la regla que vemos en los numerosísimos anuncios pu-

1 Traducción de $\mathrm{M}^{\mathrm{a}}$ Begoña Sánchez Galán (Universidad de Valladolid).

2 Profesor de Comunicazione Pubblicitaria en la Università di Modena e Reggio Emilia, Italia. Correo electrónico: vanni.codeluppi@unimore.it 
blicitarios que aparecen habitualmente en los medios impresos con motivo de las presentaciones de las colecciones de temporada: mensajes exageradamente pobres basados en una modalidad comunicativa autorreferencial.

En los últimos años han aparecido signos de un cambio progresivo en esta situación. El sector del vestido parece haber iniciado una nueva fase de su historia: el prêt-à-porter, el vestuario asequible que lleva el signo inconfundible de la creatividad de un diseñador, cede su lugar cada vez más a la afirmación de la marca, sujeto abstracto y libre de vínculos con individuos concretos. El sector del vestido está empezando a entender la importancia de capitalizar la imagen de marca, con inversiones encaminadas a producir una estabilidad en el tiempo. Este proceso no solo está motivado por la edad avanzada de algunos diseñadores, ni por el hecho de que carezcan de herederos a los que dejarles su actividad, sino sobre todo por las notables dimensiones económicas que han alcanzado muchas de las marcas más importantes, obligadas en consecuencia a desarrollar alianzas con otras empresas o con grandes grupos financieros, y por lo tanto a adoptar estrategias de comunicación que tienen como objetivo principal la valorización de la imagen de marca.

Es evidente que la publicidad del vestido es una realidad extremadamente heterogénea de la que no es posible hacer una valoración unívoca. En general, sin embargo, este tipo de comunicación presenta un aspecto aparentemente pobre con respecto a la riqueza comunicativa que caracteriza, por ejemplo, a los desfiles y a los puntos de venta de este mismo sector, o a la publicidad de los perfumes lanzados por las mismas marcas de ropa. Pero es pobre, sobre todo, con respecto a la profusión de signos que distingue e identifica habitualmente el mundo publicitario de otros ámbitos productivos. Casi todas las empresas del sector del vestido utilizan principalmente los medios impresos y presentan sus propios modelos mediante fotografías que solo contienen una marca y una modelo o un modelo. Por otro lado, no recurren al registro verbal y por ello no utilizan un headline ni, mucho menos, un bodycopy.

\section{Las causas de la pobreza de la publicidad del vestido}

Son múltiples las razones que determinan la pobreza comunicativa de la publicidad del vestido. En primer lugar, existe la convicción, ampliamente extendida en el sector, de que lo que se debe presentar a los consumidores no es un producto común, sino la «moda». Esto es, una realidad diferente, rica en valores de tipo estético, y más prestigiosa y refinada que la que caracteriza a otros ámbitos empresariales. Se entiende, por lo tanto, que la comunicación del sector del vestido debe permanecer en un plano abstracto y valerse solamente de las imágenes, lenguaje primario de la estética, evitando la excesiva explicitación que conlleva la utilización del lenguaje verbal. Se piensa que introducir un texto de cualquier tipo junto al cuerpo que viste la prenda podría traducirse en un debilitamiento del poder de 
fascinación que posee dicho cuerpo. De hecho, se recurre sólo a los medios impresos porque se considera que están dotados de mayor prestigio, al menos cuando el mensaje aparece en las cabeceras de moda más importantes.

La segunda razón reside en la exigencia de la empresa de controlar integralmente los productos a todos los niveles en los que opera: desde el nivel del aspecto estilístico hasta, precisamente, el de la publicidad. Es escaso, por lo tanto, el recurso a agencias y creativos publicitarios ajenos a la empresa. Y escasa es, en consecuencia, la utilización de prácticas dedicadas a la gestión de las posibilidades de comunicación.

La tercera razón tiene que ver con la prevalencia de la voluntad de comunicar, más que al consumidor final, a la competencia y al público constituido por los miembros del sector. Lo importante no es activar complejas estrategias comunicativas, sino conseguir que el anuncio ponga de manifiesto la propia existencia en un sector densamente poblado y en el que la competencia es extremadamente dinámica. Esta característica es posible gracias a que a los consumidores finales se les ofrecen otros instrumentos comunicativos específicos: las noticias de los desfiles difundidas por los medios de comunicación, los artículos en las revistas, los catálogos, las distintas formas de comunicación presentes en el punto de venta, etc.

La cuarta, y probablemente la razón más importante, es la necesidad de crear una y otra vez algo que sea diferente: innovaciones estilísticas que deben alimentar necesariamente y sin descanso los ciclos de la moda (a pesar del hecho de que la tradicional presentación semestral de las colecciones se reduce hoy en día a una pura ficción debido a la intensa aceleración sufrida en los últimos años por los ritmos de la moda). Esta necesidad deja poco tiempo para pensar y realizar mensajes articulados y originales. Como consecuencia, las empresas se centran en los productos y en el contenido estilístico que pueden ofrecer, descuidando las ricas posibilidades expresivas que son propias de la comunicación publicitaria.

De todo ello se extrae que, en la mayor parte de los casos, los mensajes publicitarios que podemos encontrar en el mundo del vestido transgreden los principios utilizados habitualmente en el ámbito de la publicidad de otros sectores, porque plantean posicionamientos de mercado débiles, a menudo solapados entre ellos y que cambian constantemente, sedimentando por ello muy poco en la mente de los consumidores.

A pesar de todo lo dicho, es posible identificar significados en muchos de los mensajes publicitarios que se producen en el sector del vestido. Mensajes que, a pesar de utilizar una gama limitada de elementos expresivos, han podido dar vida a estrategias de comunicación eficaces. De hecho, muchas veces es precisamente por su aparente debilidad comunicativa por lo que dichos mensajes son capaces de ejercer una influencia mayor, dado que superan con más facilidad las barreras defensivas de tipo racional de los consumidores. 


\section{Las estrategias de comunicación del vestido}

La eficacia de muchas de las estrategias de comunicación que se utilizan en el sector textil queda demostrada por los resultados de un trabajo de investigación realizado de manera más o menos continuada desde 1995 por el autor de estas páginas. El trabajo de investigación se ha centrado en los anuncios de prensa de la ropa femenina. No se han tenido en cuenta, para simplificar, los mensajes publicitarios de sectores complementarios al del vestido (lencería, bolsos, zapatos, etc.), a pesar de que cada vez es más frecuente que formen parte de las estrategias de comunicación de las marcas más importantes. Los anuncios de prensa que presentaremos han aparecido en los últimos años en periódicos italianos y han sido elegidos únicamente porque estaban en situación de desempeñar una función ejemplificadora.

Se podría repetir un análisis de este tipo para el ámbito del vestido masculino, pero se considera que en la moda el sector femenino, por ser culturalmente hegemónico, debe recibir necesariamente una atención mayor. El «gran rechazo» ejercido por los hombres del siglo XIX hacia la moda sigue estando aún vigente ${ }^{3} \mathrm{y}$, como consecuencia, el traje oscuro burgués sigue siendo el modelo de vestuario masculino más importante, a pesar de que se ha iniciado un proceso de adopción de valores y sensibilidades típicamente femeninas en el modo de vestir de los hombres.

Dado el amplio número de anuncios publicitarios que ha sido necesario analizar, se ha decidido recurrir a una aproximación que presta especial atención al proceso de enunciación de los mensajes ${ }^{4}$. Dicha aproximación resulta muy eficaz para analizar los mensajes publicitarios del vestido, que presentan unas estructuras simplificadas. De hecho, habitualmente se caracterizan por presentar únicamente el cuerpo de una modelo. Dicho cuerpo desempeña, sin embargo, una función ejemplar. Es un cuerpo ideal, perfecto y deseable que, precisamente por ello, intenta representar el modelo con el que todos los destinatarios empíricos del mensaje deberían identificarse. No es una copia especular del cuerpo de los consumidores, sino un modelo de nivel superior. No le dice al que mira «tú eres», sino «tú puedes llegar a ser así gracias a estos vestidos». Por lo tanto, no se identifica de manera directa con los dos sujetos abstractos que están contenidos dentro del texto y que en términos semióticos se llaman «enunciador» (el que habla), y «enunciatario» (el que escucha). Estos sujetos no se manifiestan de manera explícita en el anuncio, a pesar de que el cuerpo de la modelo permite que el receptor del mensaje intuya indirectamente su naturaleza y la diferencia dialéctica que se establece entre ellos.

Las modalidades a partir de las cuales se busca la identificación del consumidor en el mensaje son varias, porque varias son las posibles estrategias comunicativas que el mensaje mismo puede adoptar. En su conjunto, el análisis que se ha realiza-

\footnotetext{
3 Codeluppi, V. (2007), Dalla corte alla strada. Natura ed evoluzione sociale della moda, Roma, Carocci.

4 Sobre este argumento consúltese VERÓN, E. (1983); VERÓN, E. (1985); VERÓN, E. (1987); BetTetini, G. (1984); BetTEtini, G. (1985).
} 
do en el ámbito de la publicidad del vestido ha permitido descubrir que las principales estrategias utilizadas son las seis que aparecen en la Figura 1. En esta figura las estrategias están ordenadas en base a dos criterios de clasificación:

- el tipo de efecto que se busca conseguir en el destinatario (activación de una dimensión o cognitiva o «patémica», esto es, basada en un distanciamiento cognitivo o, por el contrario, en una respuesta emocional o pasional);

- el tipo de sujeto principal de la enunciación, puesto de manifiesto por el punto de vista que adopta el mensaje y comprendido en uno de los tres pronombres personales del singular (yo, tú, él o ella), el primero de los cuales implica un relato en primera persona, el segundo una interpelación directa como interlocutor, y el tercero la impersonalidad de un relato en tercera persona.

Fig. 1. Estrategias comunicativas de la publicidad en prensa del vestido

\begin{tabular}{|c|c|c|c|}
\hline & YO & TÚ & ÉL O ELLA \\
\hline COGNITIVO & Autonomía & Inclusión & Representación \\
\hline PATÉMICO & Intimidad & Complicidad & Empatía \\
\hline
\end{tabular}

El esquema que definen dichas dimensiones tiene validez teórica, a pesar de que ha sido diseñado a partir del análisis realizado de los mensajes publicitarios mediante un método de tipo comparativo. O lo que es lo mismo, tratando de identificar las semejanzas y diferencias entre los elementos que componen los mensajes, con el fin de identificar grupos homogéneos que adoptasen la misma estrategia comunicativa $^{5}$. Dicho esquema está asociado específicamente al ámbito de esta investigación y no se puede aplicar de manera general a cualquier contexto comunicativo. Entendemos, sin embargo, que puede tener una amplia gama de aplicaciones en la publicidad de sectores muy diferentes al del vestido.

Pero pasemos ya a analizar cuáles son las características principales de cada una de las seis estrategias comunicativas que han sido identificadas y que vamos a presentar siguiendo la estructura del esquema que las agrupa. Naturalmente, estas que vamos a ver son estrategias «puras», que se ilustrarán con ejemplos lo más puros posibles, pero que en la práctica de los procesos de significación se contaminan con otras estrategias menos significativas, dando vida a híbridos «impuros».

5 DeFrance, A. (1988): «The Enunciative Contract and Media Planning», International Journal of Research in Marketing, 4, 4. 


\subsection{Autonomía}

Es la estrategia comunicativa más clásica de cuantas se aplican al campo de la publicidad del vestido y sin duda una de las más difundidas (cfr. Figuras 2 y 3 ). En ella la modelo aparenta vivir una vida autónoma. Aparece sola y ubicada en un contexto asignificante, ya sea un estudio fotográfico o una localización exterior, pero siempre sustancialmente neutro. Desde el punto de vista cromático, es habitual que se utilice un fondo neutro de colores claros, que se identifica con significantes de clase y refinamiento, pero que sobre todo sirve para resaltar visualmente el cuerpo de la modelo.

Esta última manifiesta un cierto distanciamiento psicológico con respecto al enunciatario, como puede apreciarse en la mirada, generalmente fría, ausente y que por lo general no se dirige al lector, cosa que sucede también con su cuerpo. Como resultado se obtiene una situación de desvalorización del enunciatario, en tanto en cuanto este último no es tenido en cuenta de manera sustancial, ni queda claramente definido. La modelo, por ello, tiende a relacionarse solo con el enunciador. Se encuentra en una situación de superioridad con respecto al enunciatario y se centra en su propio ser, dotado de un estatuto más elevado que el del destinatario.

En general, esta estrategia se caracteriza también por una cierta estereotipia, en tanto en cuanto la modelo se encuentra en una clara actitud de pose y queda por ello asociada a dicho convencionalismo iconográfico, relacionado históricamente con el ámbito de la fotografía de moda. Convencionalismo que se caracteriza por una importante falta de naturalidad en la postura de la modelo con respecto a las posturas habituales del cuerpo y que se obtiene sobre todo a partir de una enfatización de los miembros, que son decididamente separados del busto.

Fig. 2.

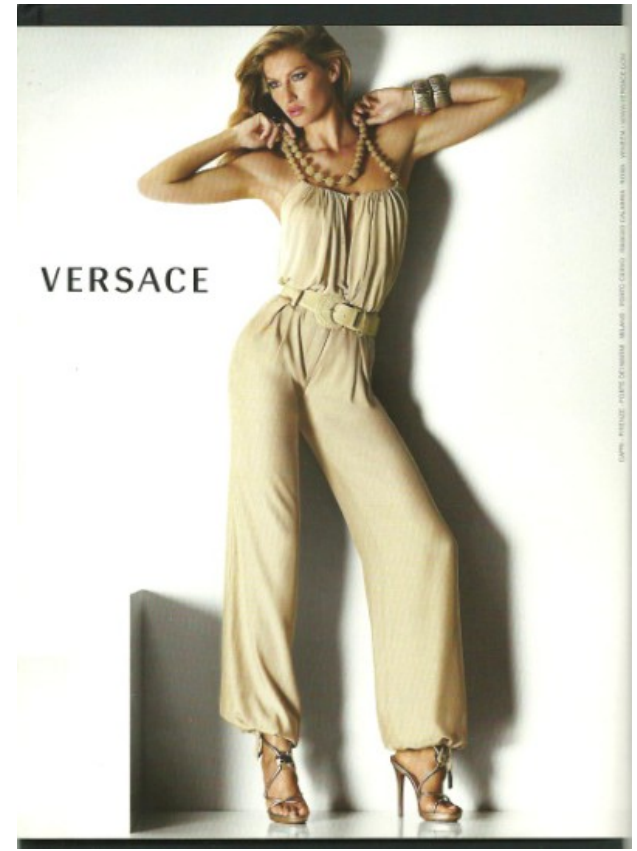

Fig. 3.

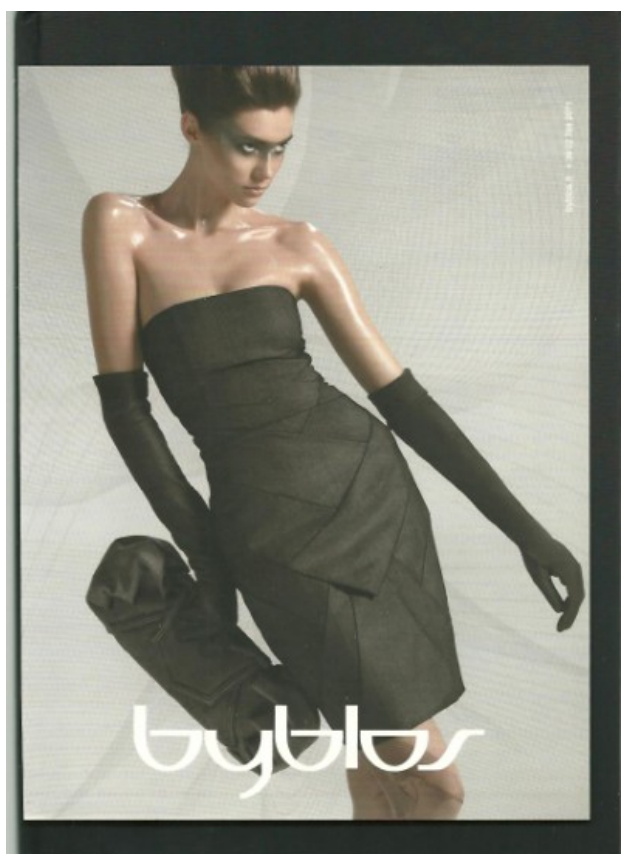




\subsection{Intimidad}

El contexto sigue siendo absolutamente asignificante y el énfasis del discurso sigue estando en el Yo de la modelo (cfr. Figuras 4 y 5). Sin embargo, en esta ocasión el nivel de implicación del destinatario es mayor, porque la estrategia está orientada a «desnudar» la intimidad profunda de la modelo. Esta última abandona los convencionalismos de la pose fotográfica clásica y asume una postura más natural que le permite comunicar que su intención no es interpretar un papel profesional, sino exteriorizar su esfera privada y subjetiva.

Para ello se muestra frágil e indefensa y, precisamente por ello, parece tener la capacidad de implicar en mayor medida, y desde un punto de vista psicológico, al destinatario. Expresa la intención de que este último entre en el interior de sus pensamientos y en su mundo interior. No le muestra el cuerpo, ni los ojos, que generalmente están cerrados o semicerrados, y que ya no son fríos y distantes, sino íntimos, porque miran hacia el interior. Los miembros de la modelo, por otro lado, permanecen pegados al cuerpo. En algunos casos lo protegen, casi como si quisieran indicar que intenta defenderse del exterior.

Fig. 4.

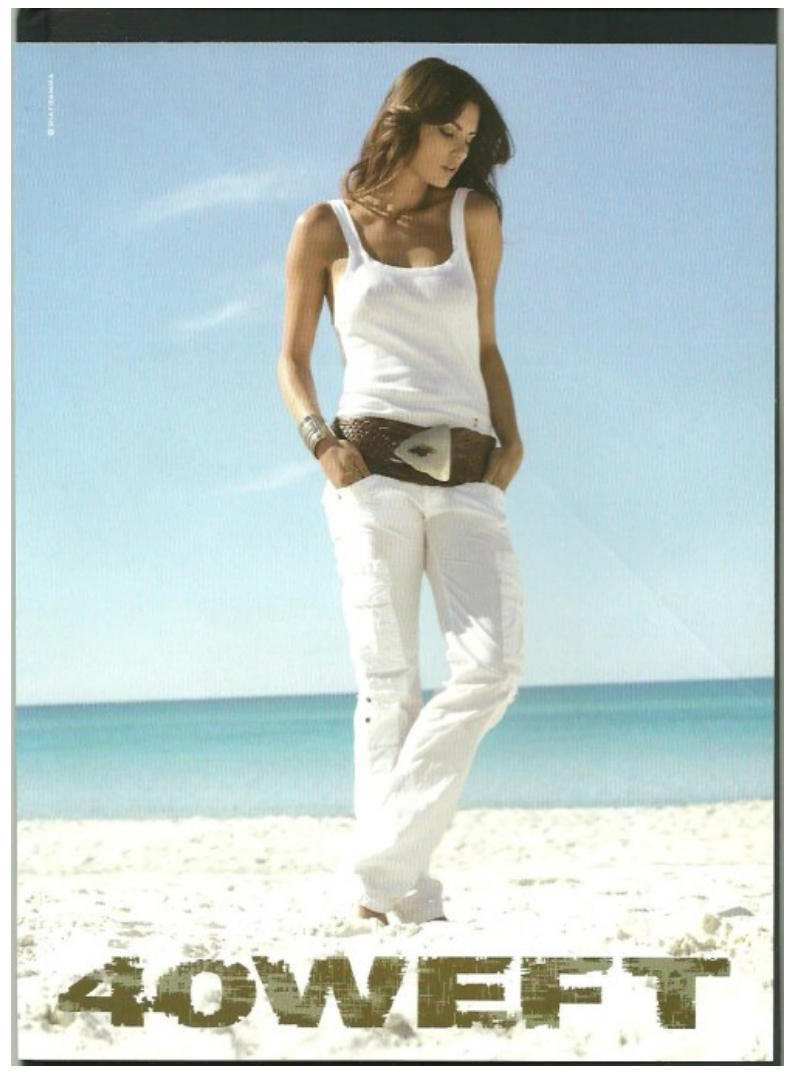

Fig. 5.

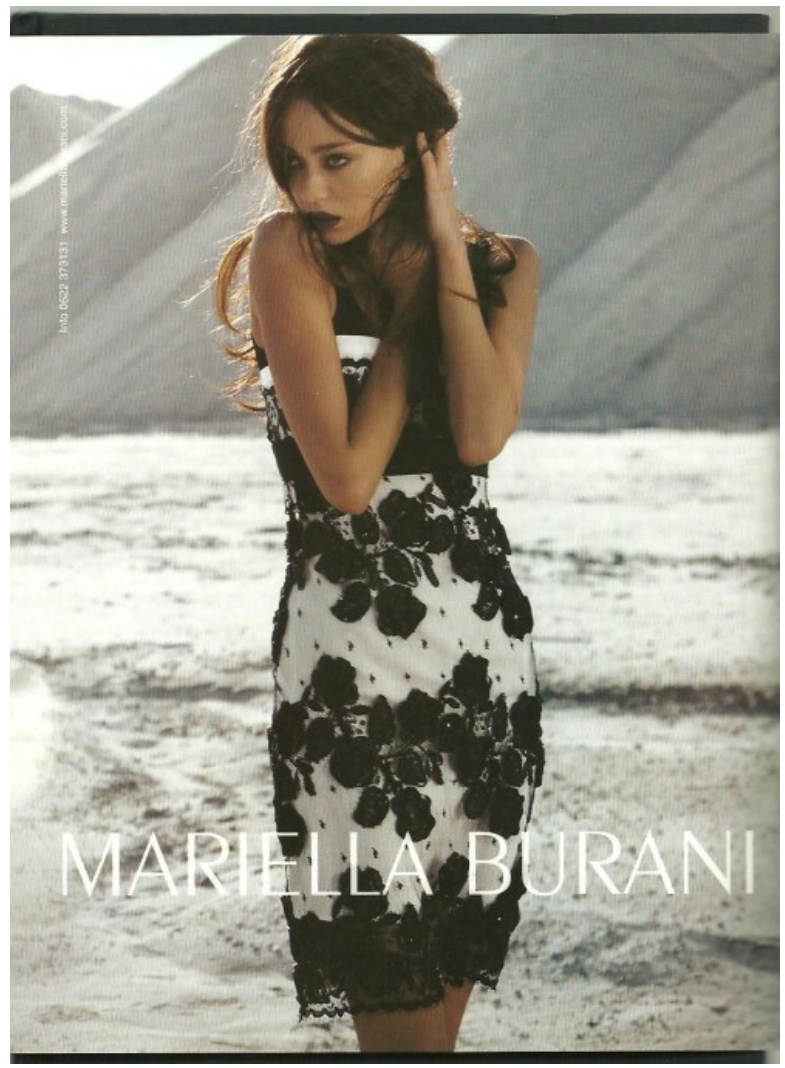




\subsection{Inclusión}

En esta, que es probablemente la estrategia comunicativa más extendida de cuantas hemos identificado, el énfasis se sitúa en el Tú del interlocutor, que el mensaje intenta sin lugar a dudas incluir en su interior (cfr. Figuras 6 y 7). Es cierto que en el centro de la representación se encuentra siempre el Yo de la modelo, pero ésta intenta interpelar directamente al destinatario. Lo hace sobre todo con la mirada, que como ya sabemos tiene un fuerte efecto de implicación en el que es mirado, pero por lo general el cuerpo entero está dirigido hacia el destinatario y habla por ello directamente con él.

La modelo suele estar siempre posando y no pone en escena sus rasgos más profundos, sino que intenta implicar al destinatario a partir de distintas expresiones y posturas. Es evidente que en la estrategia de Inclusión el enunciador tiende a construir al enunciatario como co-enunciador del mensaje, poniendo al receptor en su mismo plano e implicándolo directamente en el proceso de enunciación.

Fig. 6.

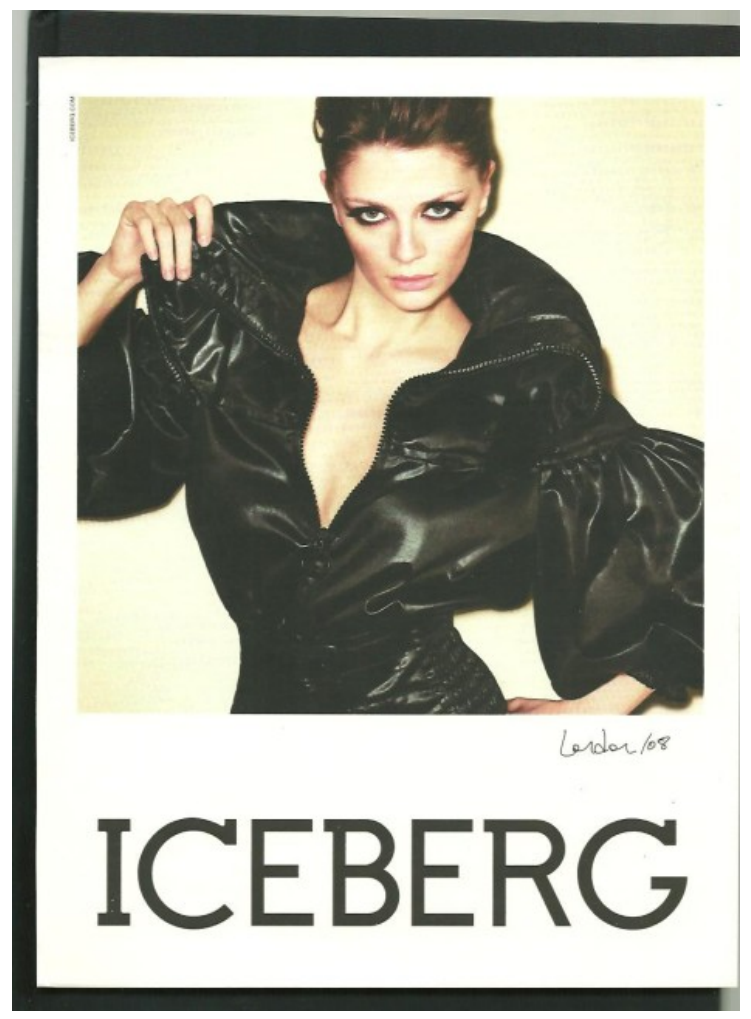

Fig. 7.

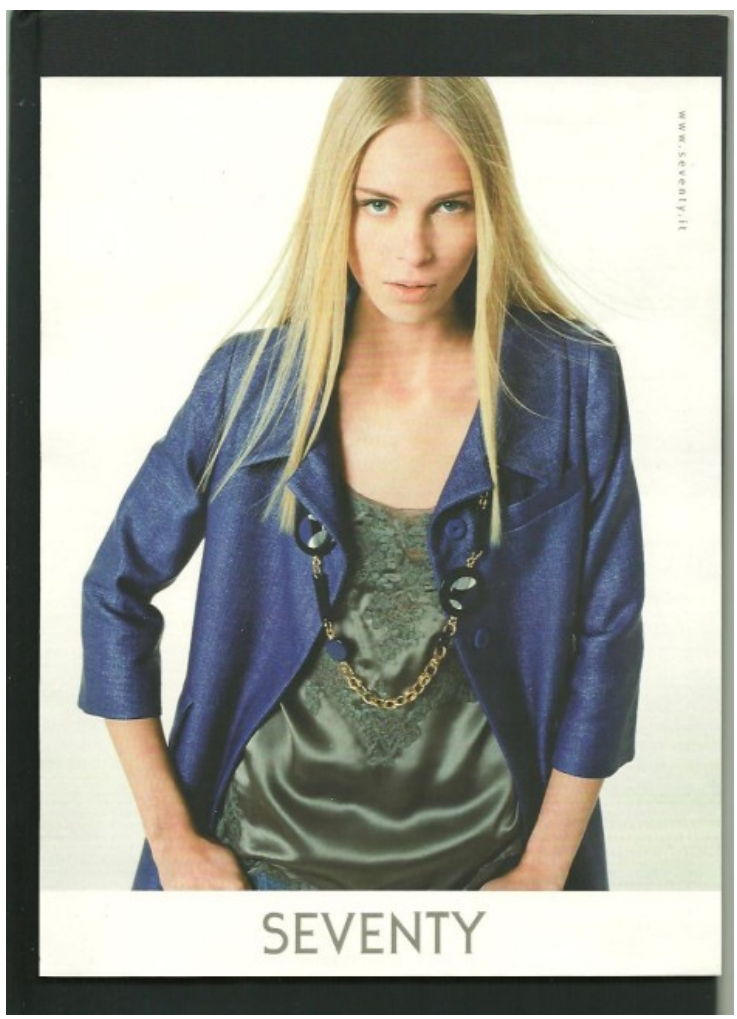




\subsection{Complicidad}

El objetivo de esta estrategia es obtener un nivel de implicación del destinatario superior a la anterior, a la que aparentemente se parece (cfr. Figuras 8 y 9). La modelo se sigue dirigiendo claramente hacia el destinatario, pero en este caso su mirada está acompañada de una expresión cautivadora y de una postura corporal que secunda todo aquello que expresa el rostro.

$\mathrm{Su}$ mirada ya no es directa, sino transversal con respecto al observador. El cuerpo también sigue a la mirada, en tanto en cuanto está situado en 3/4 con respecto al espectador. Como consecuencia, la modelo parece intrigante y maliciosa, algunas veces incluso veladamente sexy, pero en cualquier caso, precisamente por ello, está en condiciones de implicar con eficacia al destinatario desde un punto de vista psicológico.

En esta estrategia está presente una búsqueda de complicidad que tiende a convertir al enunciatario en un co-enunciador del mensaje; porque el contexto no es importante y el énfasis está en la relación que existe entre los dos actores del proceso comunicativo.

La Inclusión y la Complicidad, precisamente porque incluyen a un sujeto, pueden al mismo tiempo excluir a otro. Se trata, por lo tanto, de estrategias selectivas que conllevan algunos riesgos en términos de eficacia publicitaria.

Fig. 8.

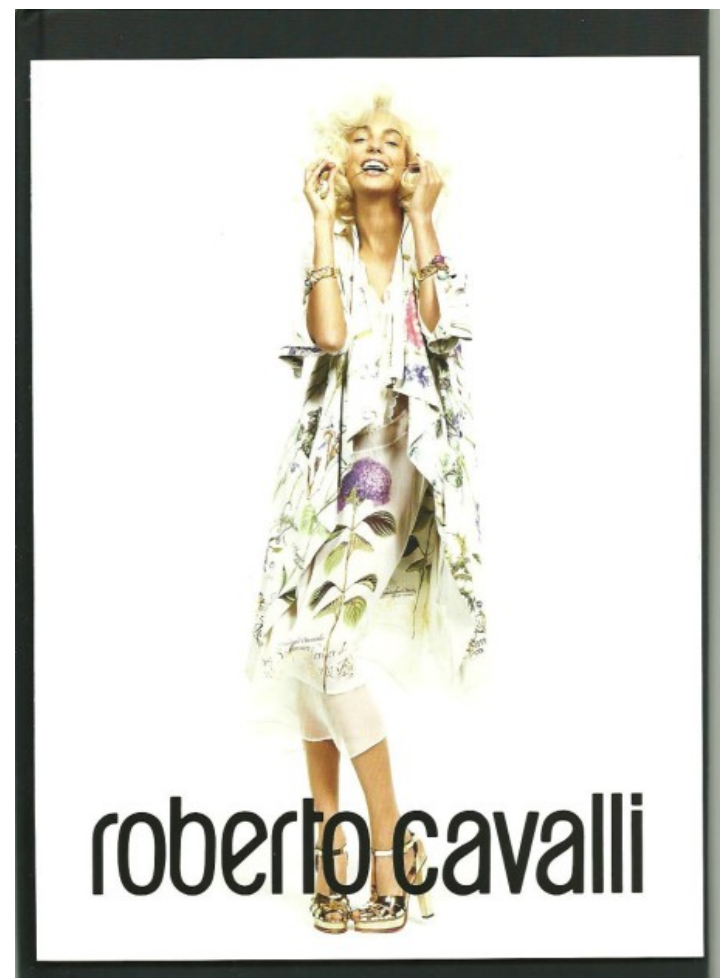

Fig. 9.

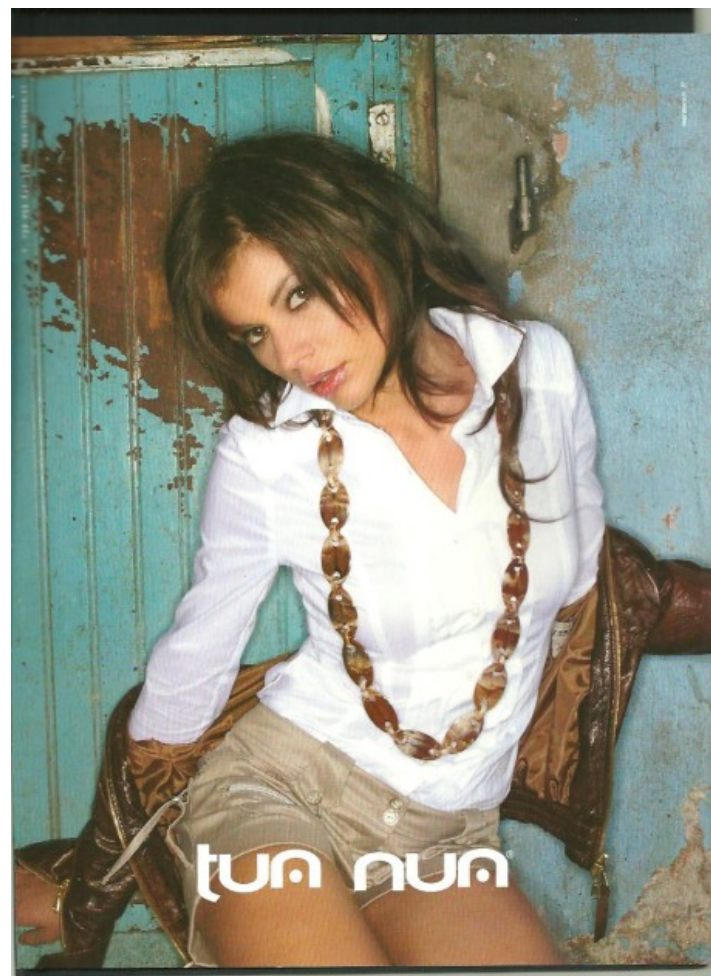




\subsection{Representación}

En esta estrategia prevalece la objetividad de una verdadera puesta en escena, en el centro de la cual se sigue situando la modelo, pero cuya importancia es sin embargo mucho más débil (cfr. Figuras 10 y 11). El énfasis suele situarse en el contexto que rodea a la modelo, que por lo tanto parece representar un simple papel narrativo en una historia contada por una tercera persona. Historia de la que se pone en escena solo un fragmento, que lleva posteriormente al destinatario a reconstruir la evolución precisamente a partir de dicho fragmento, cuya naturaleza estereotípica le permite recapitular el desarrollo narrativo completo ${ }^{6}$.

Es esta una estrategia comunicativa que recurre de manera explícita a citas que provienen de los contextos sociales más expresivos: literarios, pictóricos, fotográficos, teatrales, cinematográficos, socioculturales (mitológicos, fabulistas, bíblicos, históricos), etc. A menudo se cita incluso una figura concreta de mujer que está presente en el imaginario colectivo contemporáneo. Podemos encontrar, por lo tanto, de vez en cuando, a la femme fatale, a la sophisticated lady, a la «mujer ejecutiva», etc.

Fig. 10.

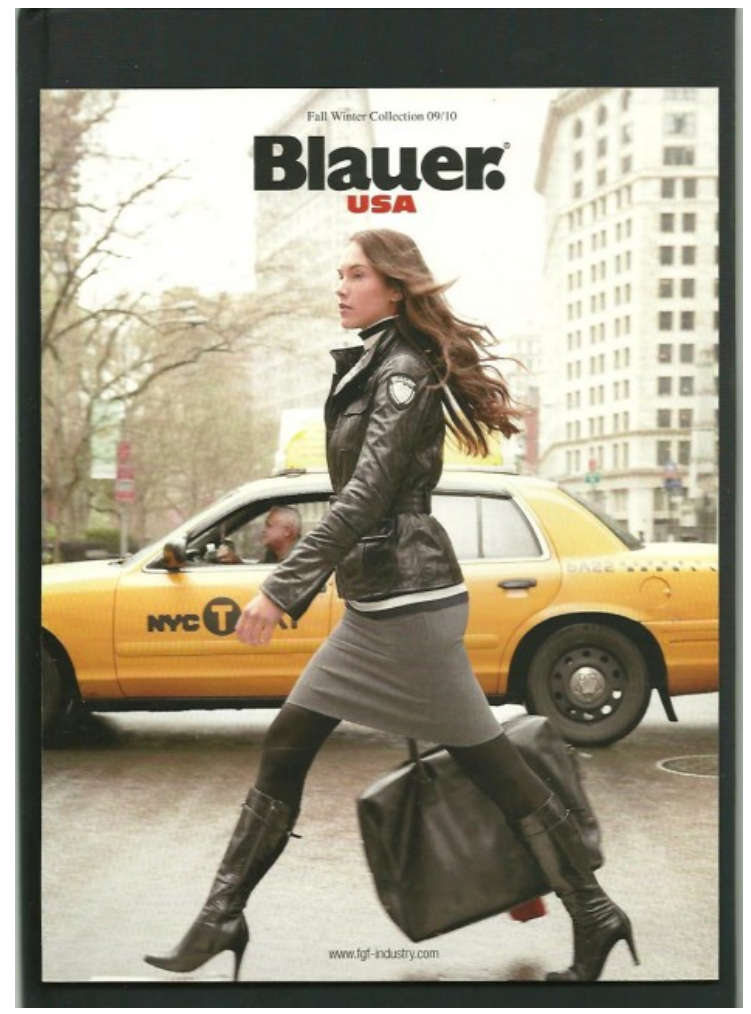

Fig. 11.

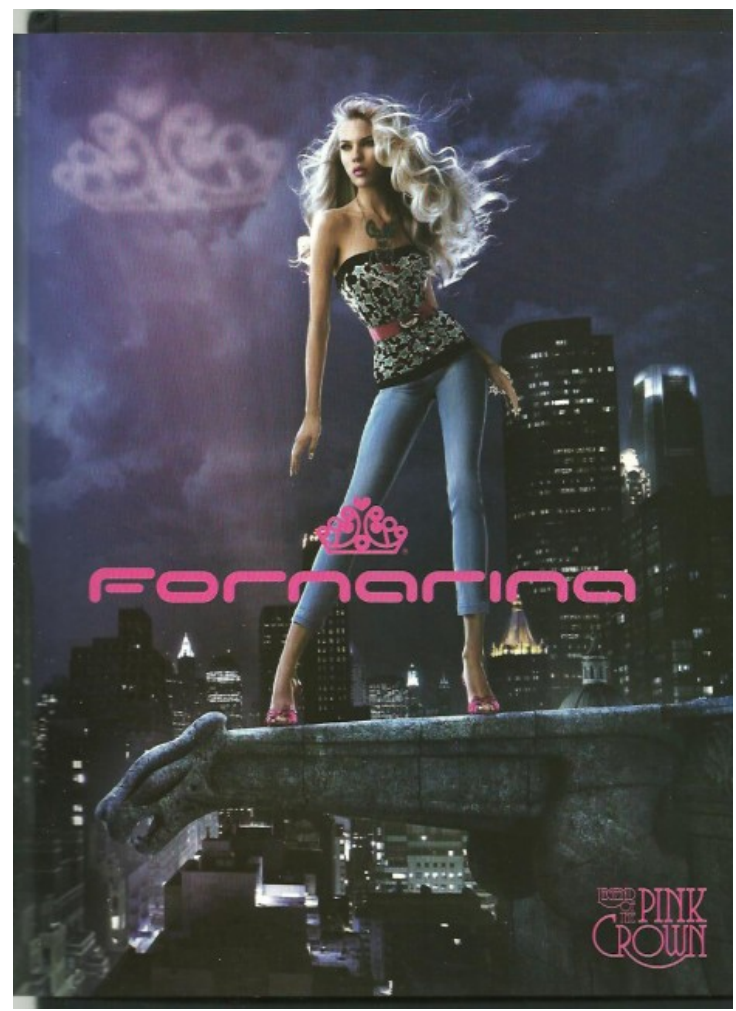

6 Goffman, E. (1979): Gender Advertisements, New York, Harper \& Row. 


\subsection{Empatía}

Vuelve a tratarse de una representación narrada en tercera persona, pero esta vez, en lugar de situarse en el interior de una historia claramente reconocible, la modelo se sitúa en un ambiente poco definido y que tiende a ser el protagonista principal de la estrategia comunicativa (cfr. Figuras 12 y 13). Lo que prevalece es, de hecho, la atmósfera estetizante, el mood, la sensación psicológica que se ha suscitado. Se trata de un mensaje que intenta establecer una sintonía con el mundo interior del destinatario, que intenta constituir una representación fiel del mismo. Es una estrategia comunicativa que caracteriza habitualmente a la publicidad de perfumes, pero que aparece, si bien no con mucha frecuencia, también en la destinada al vestido.

Fig. 12.

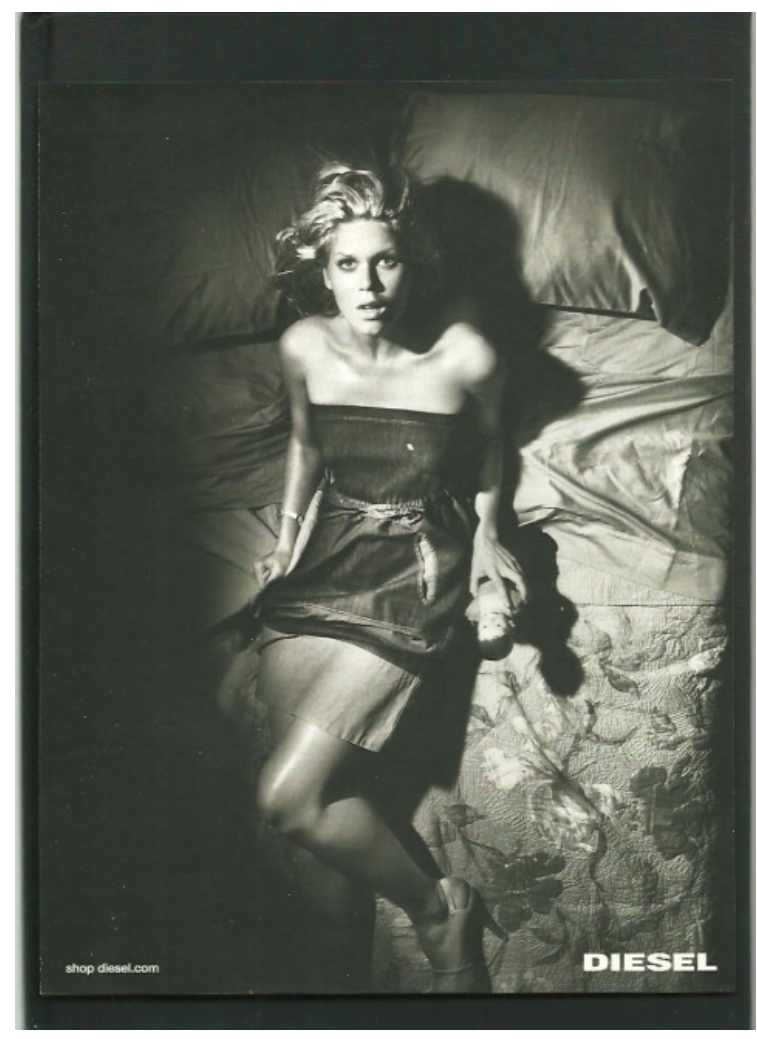

Fig. 13.

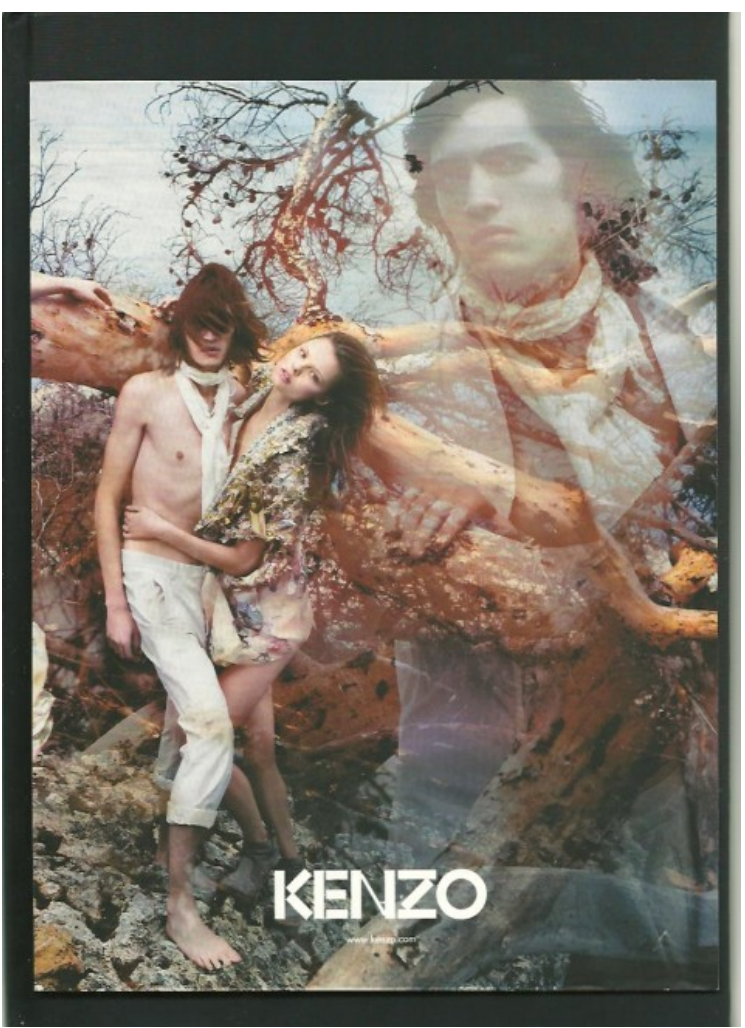

\section{Conclusiones}

El análisis que hemos realizado ha permitido demostrar que, en el interior de un universo comunicativo aparentemente pobre como es el de la publicidad del vestido, es posible aún identificar múltiples estrategias comunicativas adoptadas comúnmente para dirigirse al consumidor. Dichas estrategias suelen ser el resultado de elecciones realizadas de manera un tanto inconsciente por las empresas. Pero lo 
importante es que están presentes en los mensajes publicitarios y que quedan expuestas a la interpretación de los consumidores. Su fuerza expresiva podría ser potenciada a través del empleo de todos los signos disponibles en la modalidad comunicativa compleja de tipo verbal-visual que se utiliza habitualmente en las creatividades del resto de los sectores. Podría, de hecho, ser orientada hacia la creación de una identidad y unos códigos de marca específicos y distintivos ${ }^{7}$. En la situación actual, sin embargo, suele suceder que varias marcas utilizan la misma estrategia enunciadora, con el resultado de volver similares e indiferenciables los posicionamientos de mercado.

\section{Referencias bibliográficas}

Bettetini, G. (1984): La conversazione audiovisiva. Problemi dell'enunciazione filmica e televisiva, Milano, Bompiani.

- (1985): L'occhio in vendita. Per una logica e un'etica della comunicazione audiovisiva, Venezia, Marsilio.

CodepupPI, V. (2007): Dalla corte alla strada. Natura ed evoluzione sociale della moda, Roma, Carocci.

DeFrance, A. (1988): «The Enunciative Contract and Media Planning», International Journal of Research in Marketing, 4, 4.

FLOCH, J.-M. (1995): Identités visuelles, Paris, PUF.

GofFMAN, E. (1979): Gender Advertisements, New York, Harper \& Row.

VERON, E. (1983): «Quand lire c'est faire: l'énonciation dans le discours de la presse écrite», en Aa. Vv., Sémiotique II, Paris, IREP.

- (1985): «L'analyse du contrat de lecture: une nouvelle méthode pour les études de positionnement de supports de presse», en Aa. Vv., Les médias. Expériences, reserches actuelles, applications, Paris, IREP.

- (1987): La sémiosis sociale. Fragments d'une théorie de la discursivité, Saint-Denis, Presses Universitaires de Vincennes. 